\title{
Characterization of the genomic structures and selective expression profiles of nine class I small heat shock protein genes clustered on two chromosomes in rice (Oryza sativa L.)
}

\author{
Jiahn-Chou Guan ${ }^{1}$, Tsung-Luo Jinn ${ }^{1}$, Ching-Hui Yeh $^{2}$, Shi-Pin Feng ${ }^{1}$, Yih-Ming Chen ${ }^{1}$ \\ and Chu-Yung Lin ${ }^{1, *}$ \\ ${ }^{1}$ Institute of Plant Biology, National Taiwan University, Taipei 106, Taiwan, ROC (*author for correspon- \\ dence; e-mail chuyung@ntu.edu.tw); ${ }^{2}$ Department of Life Science, National Central University, Taiwan, \\ $R O C$
}

Received 8 June 2004; accepted in revised form 21 October 2004

Key words: azetidine, characterization and expression profiles, class 1 sHSP gene family, heavy metals, Oryza sativa, reactive oxygen species

\begin{abstract}
The cytosolic class I small heat shock proteins (sHSP-CI) represent the most abundant sHSP in plants. Here, we report the characterization and the expression profile of nine members of the sHSP-CI gene family in rice (Oryza sativa Tainung No.67), of which Oshsp16.9A, Oshsp16.9B, Oshsp16.9C, Oshsp16.9D and Oshsp17.9B are clustered on chromosome 1, and Oshsp17.3, Oshsp17.7, Oshsp17.9A and Oshsp18.0 are clustered on chromosome 3. Oshsp17.3 and Oshsp18.0 are linked by a 356-bp putative bi-directional promoter. Individual gene products were identified from the protein subunits of a heat shock complex (HSC) and from in vitro transcription/ translation products by two-dimensional gel electrophoreses (2-DE). All sHSP-CI genes except $O$ shsp $17.9 B$ were induced strongly after a 2-h heat shock treatment. The genes on chromosome 3 were induced rapidly at 32 and $41{ }^{\circ} \mathrm{C}$, whereas those on chromosome 1 were induced slowly by similar conditions. Seven of these genes, except $O s h s p 16.9 D$ and $O \operatorname{shsp} 17.9 B$, were induced by arsenite (As), but only genes on chromosome 3 were strongly induced by azetidine-2-carboxylic acid (Aze, a proline analog) and cadmium (Cd). A similar expression profile of all sHSP-CI genes at a lower level was evoked by ethanol, $\mathrm{H}_{2} \mathrm{O}_{2}$ and $\mathrm{CuCl}_{2}$ treatments. Transient expression assays of the promoter activity by linking to GUS reporter gene also supported the in vivo selective expression of the sHSP-CI genes by Aze treatment indicating the differential induction of rice sHSP-CI genes is most likely regulated at the transcriptional level. Only Oshsp16.9A abundantly accumulated in mature dry seed also suggested additionally prominent roles played by this HSP in development.
\end{abstract}

Abbreviations: ACD, $\alpha$-crystallin domain; As, arsenite; Aze, L-azetidine-2-carboxlyic acid; Cd, cadmium; GUS, $\beta$-glucuronidase; HSC, heat shock complex; HSE, heat shock response element; ROS, reactive oxygen species; sHSP, small heat shock protein; sHSP-CI, class I small heat shock protein; 2-DE, two-dimensional gel electrophoresis

\section{Introduction}

The induction of HSPs and thermotolerance in plants are highly correlated in a time- and temperature-dependent manner. Based on this correlation, it has been hypothesized that accumulation of HSPs is essential for plants to prevent and recover from heat damages (Key et al., 1981; Lin et al., 1984). Plants synthesize HSPs of diverse spectrums in response to heat stress, but the roles 
of individual HSP families in stress tolerance are different. sHSP and ClpB/HSP100 families are necessary for specific adaptation processes involved in acquired thermotolerance. Other HSP families such as HSP60s, HSP70s, and HSP90s also contribute to thermotolerance, but in general they appear to be important for growth at elevated temperatures (Hong and Vierling, 2000). Genetic and biochemical evidences have shown that sHSPs are essential for thermotolerance in Neurospora crassa (Plesofsky-Vig and Brambl, 1995), Synechcystis sp. strain PCC6803 (Nakamoto et al., 2000), and Saccharomyces cerevisiae (Haslbeck et al., 2004). Overexpression of a sHSP also resulted in increased thermotolerance of carrot suspension cells and tobacco plants (Malik et al., 1999; Sanmiya et al., 2004).

sHSPs are the most abundant and complex subset of HSPs in plants and their synthesis is induced by a rapid increase of temperature. They are encoded by members of a multi-gene family in eukaryotes and defined by possessing a conserved $\alpha$-crystallin domain (ACD). More plant sHSPs have been found recently (Scharf et al., 2001). They are divided into at least six classes based on amino acid sequence homology, immunological cross-reactivity, and subcellular localization. Class I, II, and III sHSPs are present in both cytosol and nucleus. Members of the other three classes are localized in the plastids, endomembranes, and mitochondria. sHSP-CIs are the major sHSP in plants. In soybean, sHSP-CIs represent up to $1 \%$ of the total protein after heat-shock treatment (Hsieh et al., 1992). sHSPs typically exist as a large multimer HSC with a molecular weight ranging from 200 to $800 \mathrm{kDa}$. Numerous biochemical and structural studies have demonstrated that the chaperone activity of sHSPs functions as a reservoir for the intermediates of denatured proteins, thus preventing proteins from aggregation caused by heat damages (van Montfort et al., 2001).

The expression of the heat shock genes is mainly attributed to activation of the heat shock factors (Hsf) under heat stress. Hsfs as trimers recognize the highly conserved HSE, which has been defined as adjacent and inverse repeats of the motif $5^{\prime}$-nGAAn-3', such as 5'-nGAAnnTTCnnGAAn-3' (Schöffl et al., 1998). In addition to heat stress, alcohol (Kuo et al., 2000), amino acid analogs (Lee et al., 1996), chilling (Sabehat et al., 1998) and heavy metals such as As and Cd (Lin et al., 1984; Edelman et al., 1988; Tseng et al., 1993) also induce expression of one subset of sHSP genes. Recent microarray studies in Arabidopsis revealed that a subset of sHSP genes was induced by various stresses such as salt, drought, chilling, oxidative stress, and wounding (Desikan et al., 2001; Cheong et al., 2002). Moreover, members of the sHSP gene families are also developmentally regulated in seeds, storage organs, and vegetative tissues in plants (Wehmeyer and Vierling, 2000; Lubaretz and Nieden, 2002; Jofré et al., 2003). The chaperone function of sHSP is usually emphasized under heat stress condition; however, the versatile expression patterns strongly suggest that sHSP may be important for other stresses and developmental conditions. Although it is known that the above described stresses elicit sHSP expression, the molecular mechanisms underlying the induction and the relationship between heat stress and other stresses remain unclear.

Rice plant is sensitive to heat stress at all stages of development (Maestri et al., 2002). Because of the distinct abundance and complexity of sHSP-CI in rice, much research has concentrated on the identification of sHSP-CI genes in our laboratory (Tseng et al., 1993; Tzeng et al., 1993; Lee et al., 1995; Chang et al., 2001; Guan et al., 2003). In this report, we identified and characterized nine members of the rice sHSP-CI gene family on chromosome 1 and 3 and examined during seed maturation and the effects of various stresses including HS, Aze, As, $\mathrm{Cd}$, and ethanol on expression profiles of these genes in etiolated seedlings. Our results indicate that different mechanisms may be involved in the selective induction of sHSP-CIs by heat stress and chemical agents.

\section{Materials and methods}

\section{Plant materials}

Rice (Oryza sativa L. cv. Tainung No. 67) seedlings were germinated in rolls of moist paper towels at $28{ }^{\circ} \mathrm{C}$ in a dark growth chamber as described by Lin et al. (1984). Tainung No.67 belongs to the japonica subspecies and is widely grown in paddy fields in Taiwan. Three-day-old rice seedlings without endosperms were incubated in shaking buffer $(1 \%(\mathrm{w} / \mathrm{v}))$ sucrose and $5 \mathrm{mM}$ 
potassium phosphate buffer $\mathrm{pH}$ 6.0) in shaking baths at various temperature regimes. For seed development, rice plants were grown in a $28{ }^{\circ} \mathrm{C}$ growth chamber with a 16-h day length. For chemical stress treatments, seedlings were incubated at $28{ }^{\circ} \mathrm{C}$ in shaking buffer with added chemicals as indicated. Samples were harvested and flash-frozen in liquid nitrogen and stored at $-80{ }^{\circ} \mathrm{C}$ for subsequent RNA or protein extraction.

\section{$R N A$ isolation and $R T-P C R$}

Samples were ground in liquid nitrogen using a mortar and pestle. Total RNA was extracted using TRIZOL reagent (Invitrogen, Rockville, Maryland, USA) according to the manufacturer's protocol. The quantity of total RNA was determined by optical density measurement using a Hitachi U3200 UV spectrophotometer. Total RNA $(1 \mu \mathrm{g})$ was treated with one unit of DNase I (Promega, Madison, WI, USA) for $30 \mathrm{~min}$ at room temperature prior to RT-PCR to remove residual DNA contamination. The RT-PCR analyses were conducted using Superscript one-step RT-PCR kit
(Invitrogen, Rockville, Maryland, USA) according to the manufacturer's protocol. Table 1 shows gene-specific primers for the nine genes examined in this study. Sixteen nanograms of total RNA were reverse transcribed into cDNA using random primer, $d(\mathrm{~N})_{6}$, and then amplified with gene specific primers (10 pmol for each primer) in the same tube. For each RT-PCR reaction, a pair of plant $18 \mathrm{~S}$ internal standard primers (Ambion, Austin, TX, USA) was conducted as an internal PCR control. PCR reactions for all genes were subjected to 25 cycles of $95{ }^{\circ} \mathrm{C}(30 \mathrm{~s}), 54{ }^{\circ} \mathrm{C}(30 \mathrm{~s})$, and $72{ }^{\circ} \mathrm{C}(30 \mathrm{~s})$ with GeneAmp PCR System 2400 (Perkin-Elmer Applied Biosystems, Foster City, CA, USA). For all treatments, three replicates of RT-PCR were conducted with three batches of total RNA samples isolated independently. DNA from $10 \mu \mathrm{l}$ of each PCR reaction was fractionated by electrophoresis through a $2.0 \%(\mathrm{w} / \mathrm{v})$ agarose gel with $0.01 \%(\mathrm{w} / \mathrm{v})$ ethidium bromide in $0.5 \times$ Tris-borate EDTA buffer. The gels were digitally photographed with a FloGel-1 fluorescent gel digital imaging system (TOPBIO, Taipei, Taiwan). Scion Image for Windows (Scion, http://

Table 1. Oligonucleotide primers used in RT-PCR.

\begin{tabular}{|c|c|c|c|}
\hline Gene & Primer & Sequence & Products (bp) \\
\hline \multirow[t]{2}{*}{ Oshsp16.9A } & $169 \mathrm{~A}-\mathrm{FW}$ & 5'-GCTCCTGAAGATGTGATCGG-3' & \multirow[t]{2}{*}{206} \\
\hline & $169 \mathrm{~A}-\mathrm{Rv}$ & 5'-CCTCAACGAGCAAGAACTAA-3' & \\
\hline \multirow[t]{2}{*}{ Oshsp16.9B } & 169B-Fw & 5'-AATGGTGAAAACGGGAGTTT-3' & \multirow[t]{2}{*}{152} \\
\hline & 169B-Rv & 5'-GCTTCGTGCAAACGCGCTCA-3' & \\
\hline \multirow[t]{2}{*}{ Oshsp16.9C } & $169 \mathrm{C}-\mathrm{Fw}$ & 5'-GAAGGAGAGAAGCTATATAC-3' & \multirow[t]{2}{*}{187} \\
\hline & $169 \mathrm{C}-\mathrm{Rv}$ & 5'-TAGCTCATTCATTCAGACTC-3' & \\
\hline \multirow[t]{2}{*}{ Oshsp16.9D } & 169D-Fw & 5'-CATATCACCGTCCGTGTTCGGCTG-3' & \multirow[t]{2}{*}{261} \\
\hline & $169 \mathrm{D}-\mathrm{Rv}$ & 5'-CATATCCGCGGTAGACAGGTACATG-3' & \\
\hline \multirow[t]{2}{*}{ Oshsp17.3 } & $173-\mathrm{Fw}$ & 5'-AGCATTGGGCTAATCTAAAA- $3^{\prime}$ & \multirow[t]{2}{*}{189} \\
\hline & $173-\mathrm{Rv}$ & 5'-AGAACATAATATAGTTCACT-3' & \\
\hline \multirow[t]{2}{*}{ Oshsp18.0 } & $180-\mathrm{Fw}$ & 5'-TAAGAAACTTCGGGTGTGAC-3' & \multirow[t]{2}{*}{148} \\
\hline & $180-\mathrm{Rv}$ & 5'-ATTGCTCACTTCCAACATAG-3' & \\
\hline \multirow[t]{2}{*}{ Oshsp17.7 } & $177-\mathrm{Fw}$ & 5'-AGCCCCGTTTGTTTATTCTG-3' & \multirow[t]{2}{*}{211} \\
\hline & $177-\mathrm{Rv}$ & 5'-CATTGGTACATTAATCAAGC-3' & \\
\hline \multirow[t]{2}{*}{ Oshsp 17.9A } & $179 \mathrm{~A}-\mathrm{Fw}$ & 5'-GCATCGCCGGCGTGCCGCGTGCGC-3' & \multirow[t]{2}{*}{158} \\
\hline & 179A-Rv & $5^{\prime}$-CTGACACGACGCGACACACGACTG-3' & \\
\hline \multirow[t]{2}{*}{ Oshsp 17.9B } & 179B-Fw & 5'-GATGCGATGAACACACACACACAC-3' & \multirow[t]{2}{*}{230} \\
\hline & 179B-Rv & 5'-CGTAAGGGAACTAAGATGGAACATG-3' & \\
\hline
\end{tabular}

$\mathrm{Fw}$, forward primer; Rv, reverse primer. 
www.scioncorp.com) software was used to quantify the intensity of the ethidium bromide stained DNA bands from the negative images of the gels.

\section{Primer extension analysis}

Using the AMV Reverse Transcriptase Primer Extension System (Promega, Madison, WI, USA), $10 \mathrm{pmol}$ of the gene-specific oligonucleotide, which is complementary to $2-18$ bases upstream from the start codon, was labeled at the $5^{\prime}$ terminus with $\gamma_{-}{ }^{32} \mathrm{P}-\mathrm{ATP} \quad(>5000 \quad \mathrm{Ci} / \mathrm{mmol}$, Amersham, Buckinghamshire, UK) and T4 polynucleotide kinase (Promega, Madison, WI, USA). The sequences for the gene-specific oligonucleotides are pTS3-PE (5'-GTCGGAATAGCTGCG AAT- $\left.3^{\prime}\right)$ and pYL-PE (5'-GTGTATTGTGT CTTGCTG-3') for Oshsp17.3 and Oshsp18.0, respectively. Thirty micrograms of the total RNA was annealed with 1 pmol of the labeled primer for primer extension according to the manufacture's protocol. The reaction products were electrophoresed through $6 \%(\mathrm{w} / \mathrm{v})$ polyacrylamide gel and visualized with autoradiography in parallel with the sequencing reaction products primed with the same oligonucleotide. DNA was sequenced using the Sequenase version 2.0 DNA sequencing kit (USB, Cleveland, Ohio, USA) following the manufacturer's protocol.

\section{Coupled in vitro transcription/translation and expression of recombinant proteins}

The TNT Coupled Reticulocyte System (Promega, Madison, WI, USA) was used for the characterization of the cloned sHSP gene products according to the manufacture's protocol. To use this system, the gene including the coding region and $3^{\prime}$-untranslated region (3'-UTR) was amplified by PCR and cloned into pGEM-7Zf $(+)$ vector downstream of the SP6 RNA polymerase promoter. For each construct, $1 \mu \mathrm{g}$ plasmid DNA was linearized by restriction enzyme digestion, purified and then added to the in vitro transcription/translation reaction mixture which was allowed to proceed for $1.5 \mathrm{~h}$ at $30^{\circ} \mathrm{C}$. For autoradiograph detection of the product, L- $\left[{ }^{35} \mathrm{~S}\right]-$ methionine ( $>1000 \mathrm{Ci} / \mathrm{mmol}$, Amersham, Buckinghamshire, UK) was included in the reaction mixture. The translation products were separated by 2-DE gels as described by Lin et al. (1984). For Oshsp17.9A,
Oshsp 17.9B, and Oshsp $16.9 D$, the coding region of the gene was cloned into the EcoRI and HindIII digested $\mathrm{pUC} 8$ vector and so that the recombinant proteins contained five amino acid residues (M-I-T$\mathrm{N}-\mathrm{S}$ ) before the first methionine residue. The plasmid was transformed into E. coli $\mathrm{DH} 5 \alpha$ strain and induced by addition of IPTG (final concentration, $1 \mathrm{mM}$ ) to produce the recombinant protein.

\section{Fractionation of the HSCS, 2-DE and western blotting analysis}

HSCs were purified and analyzed as described by Yeh et al. (1995). Protein samples were fractionated with ammonium sulfate (between $70 \%$ and $100 \%$ saturation). After dialysis in TE buffer (10 mM Tris and $1 \mathrm{mM}$ EDTA, pH 8.0) at $4{ }^{\circ} \mathrm{C}$ for overnight, the extracts were analyzed on a non-denaturing gradient gel (5-20\% acrylamide). A protein complex of $\sim 310 \mathrm{kDa}$ on the non-denaturing gradient gel was recovered and then further analyzed on a 2-DE gel as described by Yeh et al. (1995). For immunoblotting, proteins were transferred from acrylamide gels to Immobilon PVDF membranes (Millipore, Bedford, CA, USA). The anti-Oshsp16.9A antiserum was used as first antibody and antibodies raised in goat against rabbit $\mathrm{IgG}$, conjugated with horseradish peroxidase (Bio-Rad, Hercules, CA, USA), were used as second antibody following the user's manual. For immunological detection in Figures 5B and 7B (Aze treatment and dry embryo), the Western Lightning ${ }^{\mathrm{TM}}$ Chemiluminescence Reagent Plus (PerkinElmer Life Sciences, Boston, MA, USA) was used according to the manufacture's protocol. The KODAK BioMax Light Film (Kodak, Rochester, NY, USA) was used for chemiluminescent light detection.

\section{Chromosome mapping}

For chromosome mapping, the 3'-untranslated regions ( $3^{\prime}$-UTRs) of rice sHSP-CI genes were used as hybridization probes. Chromosomal mapping was conducted as described previously (Guan et al., 2003).

\section{Particle bombardment and transient expression assays}

The coleoptile of a etiolated rice seedling was cut from embryonic root and positioned on the 
middle of a $10-\mathrm{cm}$ Petri dish containing MS salts supplemented with $0.6 \%(\mathrm{w} / \mathrm{v})$ agarose and $3 \%$ $(\mathrm{w} / \mathrm{v})$ sucrose. The mixture (in a 1:1 molar ratio) of a test DNA construct and a maize ubiquitinluciferase internal control construct were coated onto a $10-\mu \mathrm{l}$ aliquot of $3 \mathrm{mg}$ gold particles (Shen et al., 1996). A helium biolistic particle-delivery system (model PDS-1000, Bio-Rad, Hercules, CA, USA) was used for particle bombardment. All bombardments were performed at $1350 \mathrm{psi}$ under a vacuum of $26 \mathrm{~mm} \mathrm{Hg}$, with a distance of $6 \mathrm{~cm}$ between the targets and the barrel of the particle gun. Following the bombardments, the Petri dishes were incubated at $28{ }^{\circ} \mathrm{C}$ in the dark for at least $6 \mathrm{~h}$ and then subjected to experimental treatments indicated. After incubation under heat shock or $5 \mathrm{mM}$ Aze, separately, for 2 and $4 \mathrm{~h}$, the bombarded coleoptiles were homogenized in $600 \mu \mathrm{l}$ grinding buffer (Shen et al., 1996). After centrifugation at $12,000 \times g$ at $4{ }^{\circ} \mathrm{C}$ for $15 \mathrm{~min}, 50 \mu \mathrm{l}$ of the supernatant was assayed for luciferase activity by Bright-Glo ${ }^{\mathrm{TM}}$ luciferase assay system (Promega, Madison, WI, USA) according to the technical manual. The luminescence was detected by an OPTOCOMP I luminometer (MGM Instruments, CT, USA). For the GUS activity assay, $50 \mu \mathrm{l}$ of the supernatant was diluted into $200 \mu \mathrm{l}$ of GUS assay buffer (Shen et al., 1996) and incubated at $37{ }^{\circ} \mathrm{C}$ for $20 \mathrm{~h}$. One hundred microliters of the reaction mixture was then diluted into $900 \mu \mathrm{l}$ of $0.2 \mathrm{M}$ $\mathrm{Na}_{2} \mathrm{CO}_{3}$ (pH 11.2). After aliquot every $300 \mu \mathrm{l}$ into three separate wells of a 96-well plate, the resulting fluorescence was measured in a Fluoroskan Ascent FL fluorometer (Labsystems, Helsinki, Finland). Normalized GUS activity was calculated by dividing GUS activity by luciferase activity of each respective sample.

\section{Preparations of DNA constructs}

The 631-bp promoter region of Oshsp16.9A and the 567-bp promoter regions of Oshsp17.3 and Oshsp 18.0 were separately cloned into the EcoRI and BamHI digested pGN100 vectors, a pUC19 vector bearing the $\beta$-glucuronidase (GUS) gene fused with nos termination sequence. All the promoter regions contain the regulatory sequence and $5^{\prime}$ transcribed region. All of the constructs were verified by restriction enzyme digestions and sequencing.

\section{Results}

Rice sHSP-CI gene family contains nine members

In our previous studies, we identified seven sHSP-CI genes in rice using rice $O s h s p 16.9 \mathrm{~A}$ as a screening probe (Tzeng et al., 1993; Lee et al., 1995; Chang et al., 2001; Guan et al., 2003). These genes were located on the rice chromosomes by RFLP using gene-specific 3'-UTRs. As shown in Figure 1A, Oshsp16.9A, Oshsp16.9B, and Oshsp16.9C were clustered on the short arm of chromosome 1; Oshsp 17.3, Oshsp 17.7, Oshsp17.9A, and Oshsp18.0 were clustered on chromosome 3 . Since the rice genome (cv. Nipponbare) has been completely sequenced, in order to find out if there were additional members of rice class sHSP-CI gene family, we used the conserved coding sequence encoding the ACD to search against GenBank database, and two putative genes located at chromosome 1 with high homology to sHSP-CI genes were found. Based on rice genome sequence, we cloned these genes using PCR from cultivars Tainung No.67 referring to them as Oshsp 16.9D, and Oshsp 17.9B. They were clustered closely with three genes of Oshsp16.A,Oshsp16.9B, and Oshsp16.9C previously found on chromosome 1. Amino acid alignment indicated that the sHSP-CI proteins encoded by the genes on chromosome 3 contain an insertion between the partially conserved N-terminal region and the highly conserved ACD domain (data not shown). Phylogenetic analysis with other monocot sHSP-CI genes from barley, corn, creeping bentgrass, pearl millet, and wheat, three clades were revealed in the rectangular cladogram (Figure 1B).

\section{Genomic organization and promoter sequences of the rice sHSP-CIs gene family}

Schematic diagrams of the genomic organization of the nine rice sHSP-CI genes are shown in Figure 1C. Interestingly, Oshsp17.3 and Oshsp18.0 on chromosome 3 are arranged closely in a head-to-head orientation. There are $567 \mathrm{bp}$ between the two translation start sites of Oshsp17.3 and Oshsp18.0. The nucleotide sequence of the intergenic region of Oshsp17.3 and Oshsp18.0 was shown in Figure 1D. To determine the transcription initiation sites of these two genes, we conducted primer extension analyses. The $5^{\prime}$ end of Oshsp17.3 transcripts was 
(A)

\begin{tabular}{cc}
\hline Dist \\
CM
\end{tabular} $\begin{gathered}\text { Marker } \\
\text { Name }\end{gathered}$

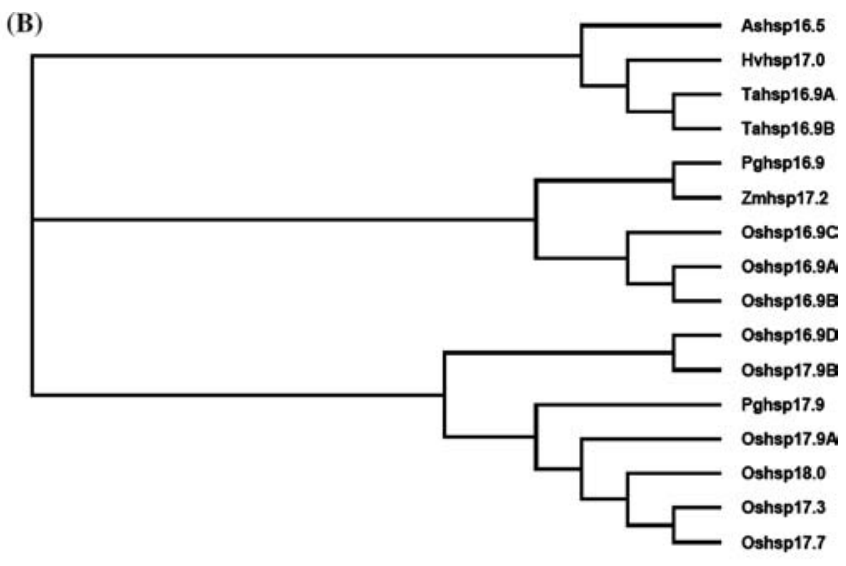

(D)

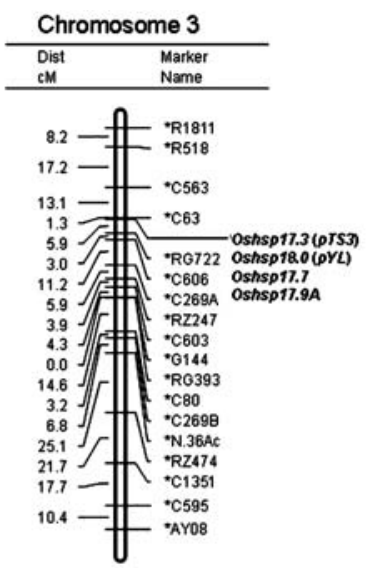

(C) $1 \mathrm{~kb}$

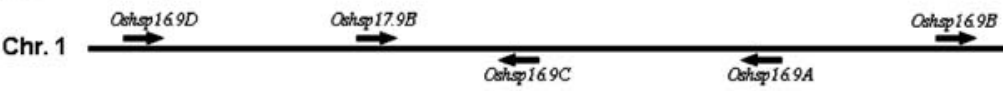

$\longrightarrow$ ashspi7.3

CAT cgtcggaata getgegaatt tggaggtgga acgatcggac ttctctgagt tcttactetg atgtttgett ggtttgcttt gcgttttctt cgtggttctg ccggtgaagg ggagegeggt TA tA box Oshsp17.3

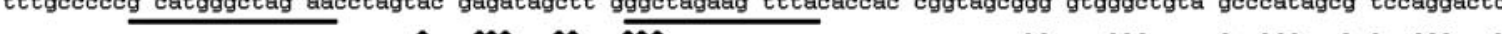

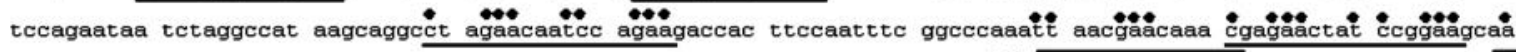

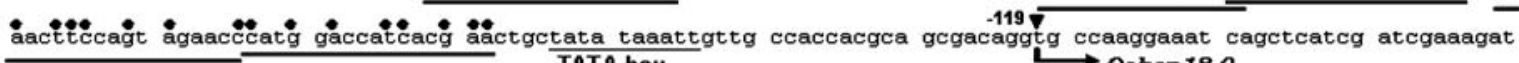
$\longrightarrow$ caacaagcte tettgagaat tgagatcace ctettccat ctagaacaca aaccagacaa cccaaaaac acaagacaca atacacaATG

(E)

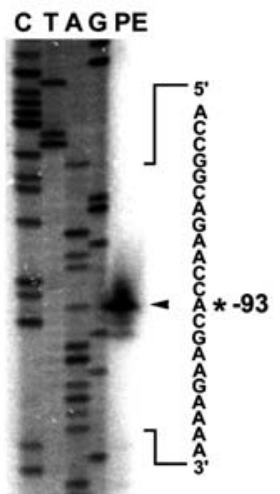

C TAGPE

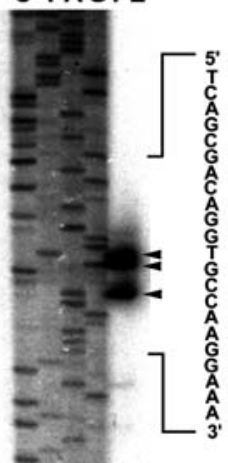

(F)
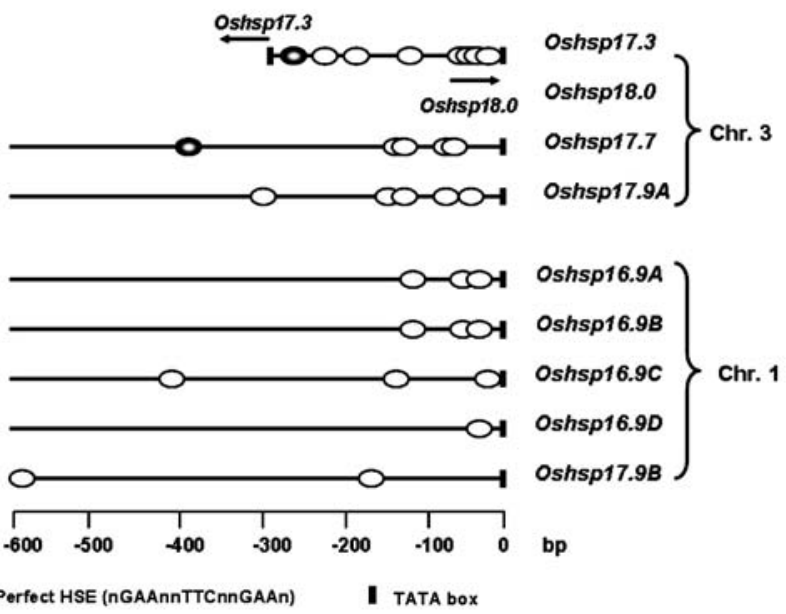

- Perfect HSE (nGAAnnTtCnnGAAn) I tATA box

$\bigcirc$ Imperfect HSE Cluster of two imperfect HSEs $\mathbb{C}$ cluster of four imperfect HSEs 
Figure 1. Chromosome location and genomic organization of members of the sHSP-CI gene family in rice. (A) The locations of rice sHSP-CI genes on chromosomes 1 and 3. Map distances are given in centimorgan (cM) to the left of each chromosome. Seven genes were mapped by RFLP using gene-specific $3^{\prime}$-UTRs as probes. The other two genes, Oshsp 16.9D and Oshsp 17.9B, are assigned to chromosome 1 based on the released sequence results of Rice Genome Sequencing Project. Names of cDNA clones of their corresponding genes are indicated in parentheses. (B) Phylogenetic analysis of monocot sHSP-CI genes. Cladogram was generated by CLUSTALW program on the basis of amino acid sequences. (C) Schematic diagrams of arrangement of the rice sHSP-CI genes on chromosome 1 (Chr.1) and chromosome 3 (Chr. 3). The transcription direction of each gene is indicated by an arrow. The intergenic region between Oshsp17.9A and Oshsp17.3 is approximate $28 \mathrm{~kb}$. (D) Nucleotide sequence of the 567-bp intergenic region between Oshsp17.3 and Oshsp18.0. The transcription start sites are indicated by arrowheads. There are $356 \mathrm{bp}$ between the two transcription start sites. The arrow indicates the transcription direction of each gene. Clusters of HSE modules are indicated by bold lines and the consensus bases are indicated by black dots. The upper cases indicate the translation start codons. (E) Identification of transcription initiation sites for Oshsp17.3 and Oshsp18.0. Lane PE shows the primer extension products of HS. Lanes C, T, A, G are from a DNA sequencing reaction in which the same primer was used. The transcription start sites are indicated by an arrowhead with a $\operatorname{star}(*)$. The number indicates the length of nucleotide upstream from the translation start site. (F) Predicted HSEs in the promoters of rice sHSP-CI genes. Approximate $0.6-\mathrm{kb} 5^{\prime}$ flanking regions were analyzed. The numbers at the bottom indicate the length of nucleotides upstream to the putative TATA box. The arrows indicate the transcription orientations of Oshsp17.3 and Oshsp18.0. The perfect HSE was defined by an interrupted pattern of three palindromic modules of five nucleotides (nGAAnnTTCnnGAAn or nTTCnnGAAnnTT$\mathrm{Cn}$ ). The imperfect HSE comprises three modules, of which at least one module with five nucleotides (nGAAn or nTTCn) and the others with invariant $\mathrm{G}$ or $\mathrm{C}$, or both AA or TT residues (such as nGnAnnnnCnnGAAn or nTTnnnGAAnnTTnn).

mapped to an 'A' residue 93 nucleotides upstream of the translation start codon (Figure 1E, left panel). The Oshsp 18.0 primer, pYL-PE, yielded three distinct extension products as indicated in Figure $1 \mathrm{E}$ (right panel). The transcription initiation sites of these two genes were also indicated in Figure 1D. Therefore, Oshsp17.3 and Oshsp18.0 are linked head-to-head and share a single 356-bp putative bi-directional promoter. Approximately 600-bp promoter regions of all the rice sHSP-CI genes were searched for HSEs according to the previous reports (Schöffl et al., 1998; Nover et al., 2001). Several clusters of HSE modules, which mediate efficient Hsf binding, were located in the promoters of seven sHSP-CI genes except Oshsp 16.9D and $O s h s p 17.9 \mathrm{~B}$, in which only one to two low-consensus HSEs were found (Figure 1F). In contrast, the highly efficient HSEs (5'nGAAnnTTCnnGAAn-3' or 5'-nTTCnnGAAn nTTCn- $3^{\prime}$ ) were found in the promoters of Oshsp17.3, Oshsp17.7, and Oshsp18.0.

\section{Seven major sHSP-CI are present in the rice HSCS}

Rice sHSP-CIs form HSCs with a molecular weight of approximate 310-kDa (Yeh et al., 1995). Purified rice HSCs were resolved by 2-DE, and five prominent protein spots were recognized after western blot analysis with anti-Oshsp16.9A antibody. To identify the gene products consisting of the HSCs, we conducted a coupled in vitro transcription/translation assay for six of the nine sHSP-CI genes. The protein products were separated by $2-\mathrm{DE}$ and the protein spot consistent with the predicted $\mathrm{p} I$ value and molecular mass for each gene product was identified (Figure 2A). A summary illustration of the components of the rice HSC separated in a 2-DE gel is shown in Figure 2B. Oshsp16.9D, Oshsp17.9A, and Oshsp17.9B were identified according to the 2-DE profiles of recombinant proteins expressed in E. coli (data not shown).

\section{The heat stress responsiveness of the rice sHSP-CI genes}

Although we knew sHSP-CI genes are expressed under heat stress, the kinetics and expression levels in rice were unclear. Thus, we monitored the expression patterns of the nine sHSP genes by RT-PCR. Primers were designed to yield PCR products with lengths between 150 and $240 \mathrm{bp}$ (Table 1). The conditions for RT-PCR were optimized to produce unsaturated PCR amplification product accumulation that reflected a linear relationship with the original transcript levels in all samples (data not shown). First, we wanted to know whether all rice sHSP-CI genes responded similarly to the temperature fluctuations. Expression profiles under increasing temperature were determined in etiolated seedlings that were exposed to $32,35,38$, or $41{ }^{\circ} \mathrm{C}$ for $2 \mathrm{~h}$. Control plants were kept at $28{ }^{\circ} \mathrm{C}$. The transcripts of the eight genes with the exception of Oshsp17.9B were easily detected at $38{ }^{\circ} \mathrm{C}$ (Figure 3). The transcript 


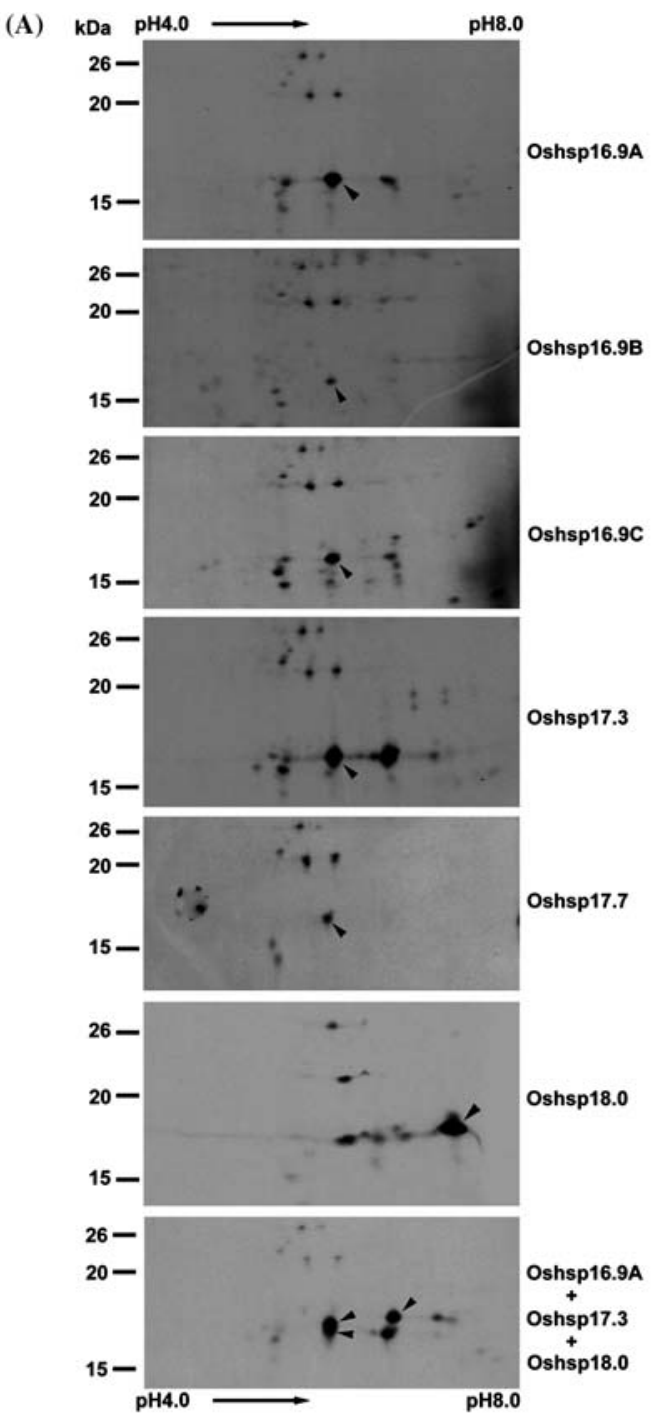

(B)

kDa

pH4.0

pH8.0

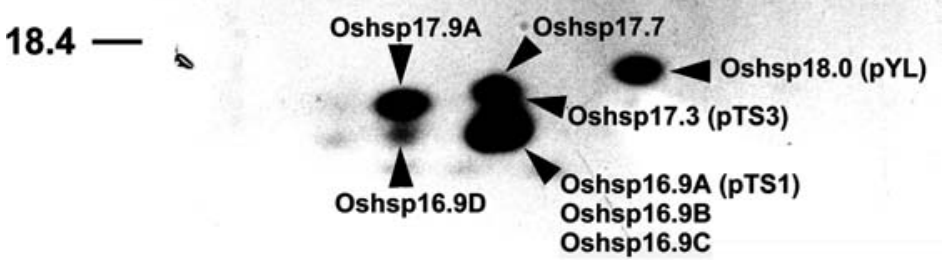

Figure 2. Identification of the sHSP-CIs consisting of heat shock complexes in rice. (A) 2-DE of ${ }^{35}$-labeled in vitro transcription/ translation products. Arrowhead indicates the product of each gene labeled on the right side. Three gene products, Oshsp16.9A, Oshsp17.3, and Oshsp18.0, which are different in molecular weight and $\mathrm{p} I$ were combined in an in vitro transcription/translation assay (bottom panel). (B) A summary illustration of the components of the purified HSCs separated in a 2-DE gel. The HSC proteins were identified by western blotting analysis. The protein spots corresponding to Oshsp16.9D, and Oshp17.9A were identified according to the western blots of the recombinant proteins expressed in E. coli. 


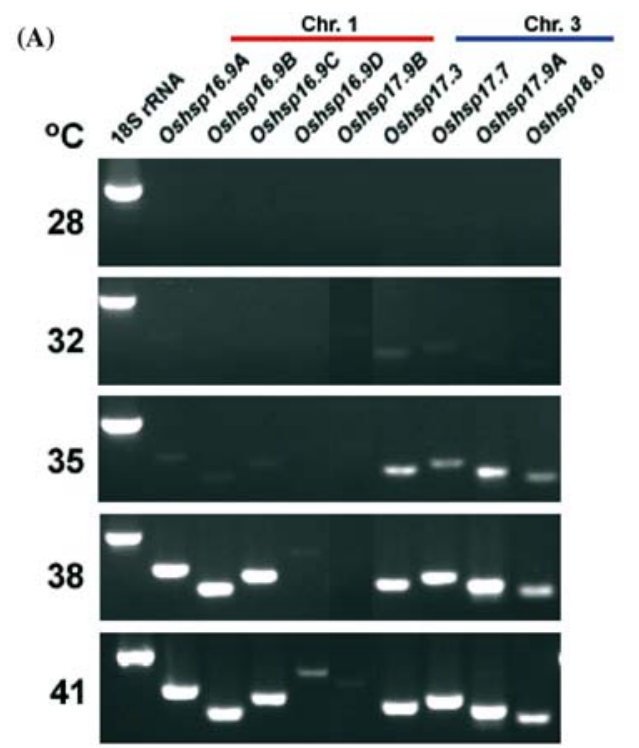

(B)

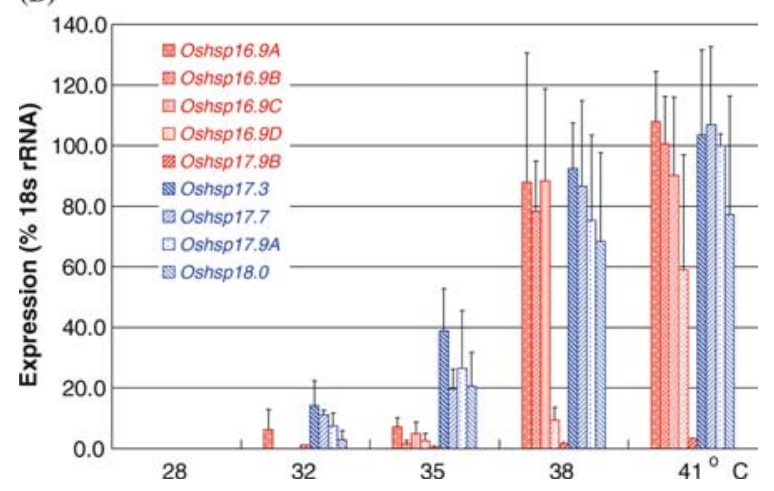

Figure 3. Expression patterns of rice sHSP-CI genes in response to temperature increase. Three-day-old rice seedlings were subjected to $28{ }^{\circ} \mathrm{C}$ (control), 32, 35, 38, and $41^{\circ} \mathrm{C}$ for $2 \mathrm{~h}$.

(A) The RT-PCR products of sHSP-CI genes were shown by ethidium bromide staining, and the RT-PCR product of the $18 \mathrm{~S}$ rRNA was used as an internal PCR control. (B) Quantification of the RT-PCR product for each gene. The resulting mean values are presented as percentage of the 18S rRNA signal value. Error bar represents $\pm \mathrm{SE}$ from three separate experiments.

of $O \operatorname{shsp} 17.9 B$ was detected at $41{ }^{\circ} \mathrm{C}$, though at a very low level. Transcripts of the sHSP-CI genes located on chromosome 3 (Oshsp17.3, Oshsp17.7, Oshsp17.9A, and Oshsp18.0) were detected at a temperature as low as $32{ }^{\circ} \mathrm{C}$ and accumulated more at $35^{\circ} \mathrm{C}$ when compared with those on chromosome 1. At $35^{\circ} \mathrm{C}$, the transcript levels of sHSP-CI genes on chromosome 3 are 3- to 4-fold higher than those of the sHSP-CI genes on chromosome 1 (Figure 3B).

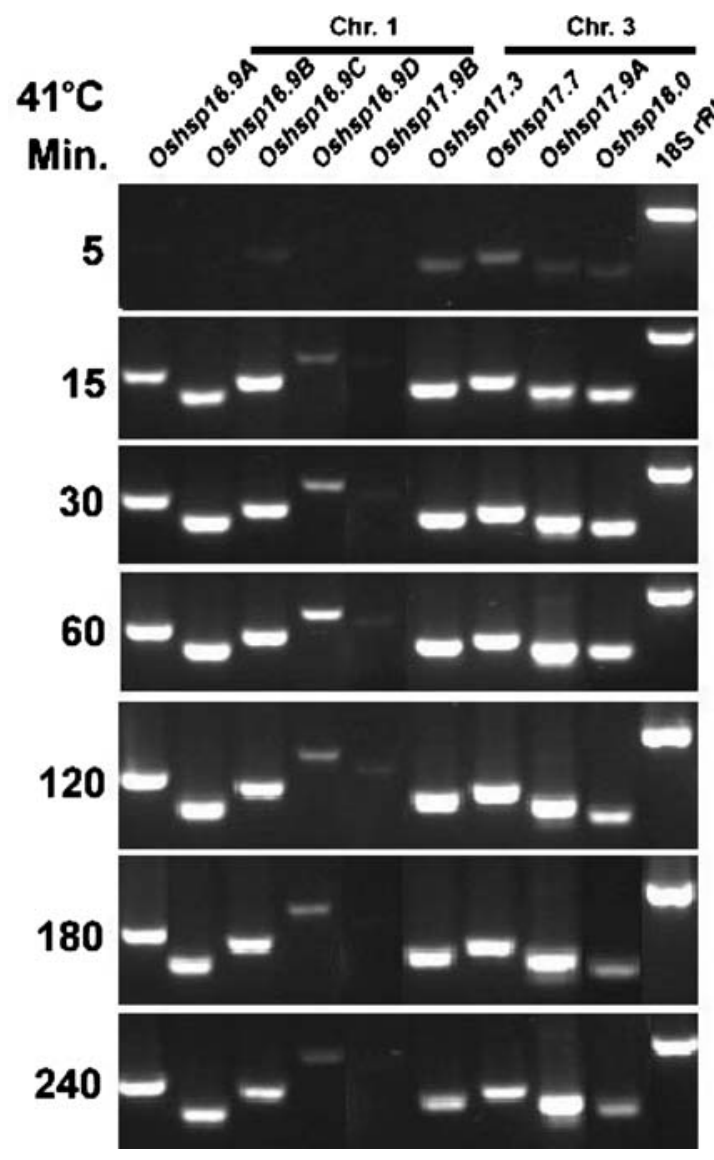

Figure 4. Time course response of the rice sHSP-CI genes under heat shock. Three-day-old rice seedlings were subject to $41{ }^{\circ} \mathrm{C}$ for $5,15,30,60,120,180$, and $240 \mathrm{~min}$. The RT-PCR products were shown by ethidium bromide staining and the RT-PCR product of the $18 \mathrm{~S}$ rRNA was used as an internal PCR control.

The levels of mRNA from sHSP-CI were analyzed by RT-PCR at different time points after initiation of the $41{ }^{\circ} \mathrm{C}$ treatment. The levels reached a maximum 30-60 min after the treatment and slowly declined afterwards (Figure 4). Osh$s p 17.9 \mathrm{~A}$ had the highest level of expression among the members studied after $1 \mathrm{~h}$ of heat shock treatment. The transcript of Oshsp16.9A declined slower than those of other sHSP-CI genes. After prolonged HS treatment $(4 \mathrm{~h})$, Oshsp $16.9 \mathrm{~A}$ transcripts only decay for $10 \%$ of the maximal level; in contrast, transcripts of the other genes decay for approximately $30-40 \%$. Similar to the expression profile at $32{ }^{\circ} \mathrm{C}$ for $2 \mathrm{~h}$ (Figure 3), the time-course experiments showed that SHSP-CI genes on chromosome 3 were induced promptly within $5 \mathrm{~min}$ of HS treatment (Figure 4). Overall, the expression 
profiles revealed that there were differences in the transcription regulation and transcript stability among the rice sHSP-CI genes.

Rice sHSP-CI genes are induced by various chemical inducers in a selective manner

Chemicals such as As, Aze, Cd, and ethanol are cytotoxic agents that cause cellular damages and have been shown to induce a HS-like response in plants. They were known to induce the expression of sHSP-CIs (Lee et al., 1996; Banzet et al., 1998); however, the characteristics of the induction were not known. We determined the transcript levels of individual sHSP-CI genes to examine whether individual members of the family respond differently to these agents. First, the time-course responsiveness of individual sHSP-CI genes by As treatment was determined. With the exception of Oshsp16.9D and Osh$s p 17.9 \mathrm{~B}$, seven out of all sHSP-CI genes were induced (Figure 5A). When the seedlings were treated with Aze, Cd, or ethanol, sHSP-CI genes on chromosome 3 were selectively induced to various degrees, whereas those on chromosome 1 showed little or no response (Figure 5A). To examine whether the RT-PCR data are reflected by changes at the protein level, we examined the total proteins from seedlings after Aze treatment by $2-\mathrm{DE}$ and western blotting analysis. As shown in Figure 5B, only proteins encoded by genes on chromosome 3 were detected.

Figure 5. Selective expression patterns of the rice sHSP-CI genes in response to chemical inducers and protein profiles of sHSP-CIs induced by Aze or HS. (A) Three-day-old rice seedlings were subject to $250 \mu \mathrm{M} \mathrm{NaAsO}, 1 \mathrm{mM} \mathrm{CdCl} 2,5 \mathrm{mM}$ Aze, $0.03 \%(\mathrm{v} / \mathrm{v}) \mathrm{H}_{2} \mathrm{O}_{2}, 500 \mu \mathrm{M} \mathrm{CuCl}_{2}$, for $2 \mathrm{~h}$, or $5 \%(\mathrm{v} / \mathrm{v})$ ethanol for $6 \mathrm{~h}$. The RT-PCR products were shown by ethidium bromide staining, and the RT-PCR product of the $18 \mathrm{~S}$ rRNA was used as an internal PCR control. (B) Identification of the sHSP-CIs by 2-DE and western blotting analysis of total proteins from seedlings. Three-day-old rice seedlings were incubated in shaking buffer at $28^{\circ} \mathrm{C}$ for $18 \mathrm{~h}$ (control), $5 \mathrm{mM}$ Aze for $18 \mathrm{~h}$ (Aze), or $\mathrm{HS}$ at $41^{\circ} \mathrm{C}$ (HS) for $2 \mathrm{~h}$. The circle indicates the protein spots corresponding to Oshsp16.9A, Oshsp16.9B, and Oshsp16.9C are absent in the Aze treatment. For each treatment, $100 \mu \mathrm{g}$ of total proteins were loaded for analysis. The chemiluminescent reagents were used for immunological detection. Exposure time to chemiluminescent film was $60 \mathrm{~s}$.
ROS may have a role in the selective induction of rice $S H S P$-CI genes in response to chemical inducers

Banzet et al. demonstrated that the synthesis of sHSP was induced by $\mathrm{H}_{2} \mathrm{O}_{2}$ in tomato cells (Banzet et al., 1998). Lee et al. found that expression of the chloroplast-localized sHSP was induced by oxidative stress and $\mathrm{H}_{2} \mathrm{O}_{2}$ in rice (Lee et al., 2000). In

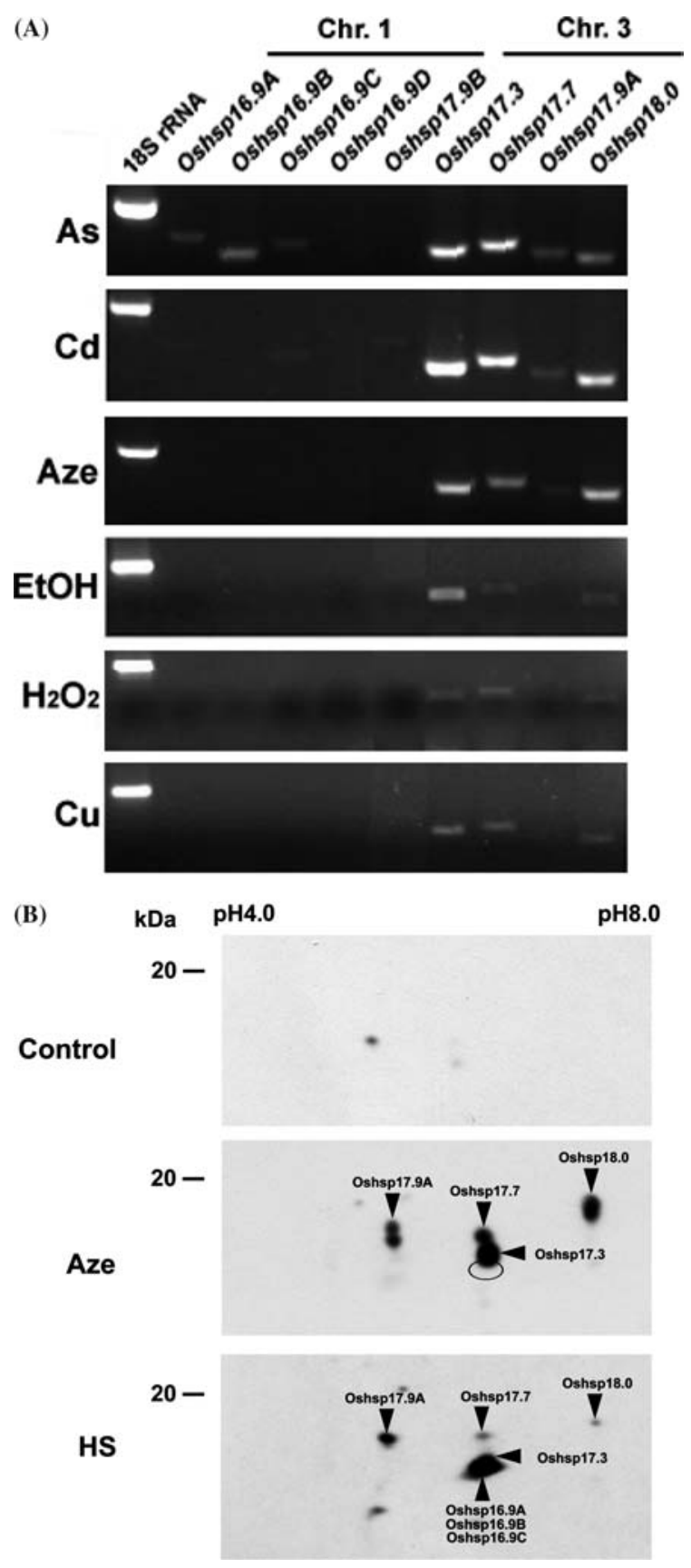


Arabidopsis, considerable evidence indicates an interlinking between responses to heat stress and oxidative stress (Panchuk et al., 2002). Thus, we determined the relationship between heat- and chemical-induced sHSP gene expressions. We treated the seedlings with $0.03 \%(\mathrm{v} / \mathrm{v}) \mathrm{H}_{2} \mathrm{O}_{2}$ and examined the responses of the rice sHSP-CI genes. $\mathrm{H}_{2} \mathrm{O}_{2}$ specifically induced Oshsp17.3, Oshsp17.7, and Oshsp18.0 (Figure 5A). The expression kinetics of these genes in response to $\mathrm{H}_{2} \mathrm{O}_{2}$ were similar to those of $\mathrm{Cd}$, Aze, and ethanol treatments (data not shown). Copper is a redox-active metal that generates ROS. We treated the rice seedlings with $\mathrm{CuCl}_{2}$ for further whether ROS was involved in the selective induction of sHSP genes. We obtained the same results as shown in Figure 5A, These findings suggest that ROS are involved in the induction of rice sHSP-CI genes as other various stresses.

Transient expression assays of the promoter activity supported the in vivo selective expression of rice sHSP-CI genes by Aze treatment

To test whether the selective induction of sHSP genes by Aze treatment observed in vivo was evoked by the differences related to promoter activity, we prepared three promoter::GUS constructs for transient expression assays by bombarded to rice coleoptiles. One construct contained a 631-bp promoter region of $O$ shsp $16.9 \mathrm{~A}$ on chromosome 1 and the other two constructs contained the 567-bp promoter region of Oshsp17.3 and Oshsp18.0 on chromosome 3 (Figure 6A). The Oshsp16.9A promoter was induced 6.2-fold by HS, but not by Aze treatment. In contrast, Oshsp17.3 or Oshsp18.0 promoter was induced over 14-fold by HS and at least 7 -fold by Aze treatment (Figure 6B). The results of transient expression assays supported the in vivo selective expression of sHSP-CI genes by Aze treatment indicating that the promoter activity is involved in differential transcription.

\section{Specific members of rice sHSP-CIs are induced during seed development}

Members of the sHSP gene families are developmentally regulated in seeds (Almoguera et al., 1998; Wehmeyer and Vierling, 2000). We analyzed the transcript levels of sHSP-CI genes in grains that were turning brown (15 days after pollination [DAP]). As shown in Figure 7A, Oshsp16.9A showed the greatest induction of the family during seed maturation. Transcript levels of Oshsp16.9B,

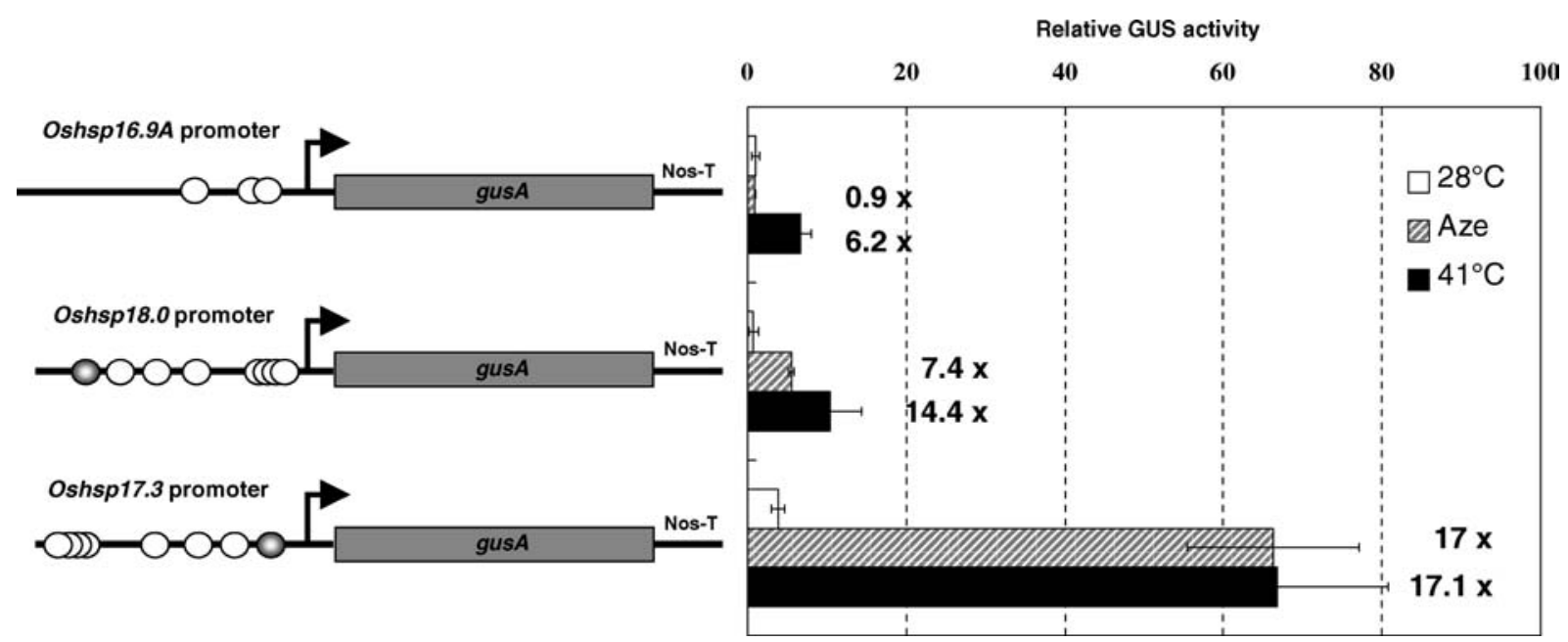

Figure 6. Transient expression assays of Oshsp16.9A, Oshsp17.3 and Oshsp18.0 promoter activity by HS and Aze treatments. Schematic diagrams of the promoter::GUS reporter constructs used in the bombardment experiments (left panel). The 631-bp promoter region of Oshsp 16.9A and 567-bp promoter regions of Oshsp17.3 and Oshsp18.0 were used for assays. The arrangements of HSEs were as indicated in Figure 1F. The GUS coding region is represented by a shade box. Nos-T is the terminator of a nopaline synthase gene. The GUS activities of all samples were normalized against those of a luciferase internal control. Bombarded coleoptiles were incubated for at least $6 \mathrm{~h}$ at $28{ }^{\circ} \mathrm{C}$, and then the samples were transferred to shaking buffer for 2-h HS treatment or 4-h Aze treatment; the samples were kept at $28{ }^{\circ} \mathrm{C}$ for overnight before GUS analysis. The magnitude of induction relative to control $\left(28^{\circ} \mathrm{C}\right)$ was indicated in the right side of bar. The data represent results of four independent transformations in an experiment. Each experiment was repeated at least two times and similar results were obtained. Bars indicate relative GUS activities $\pm \mathrm{SE}$ from four independent transformations. 


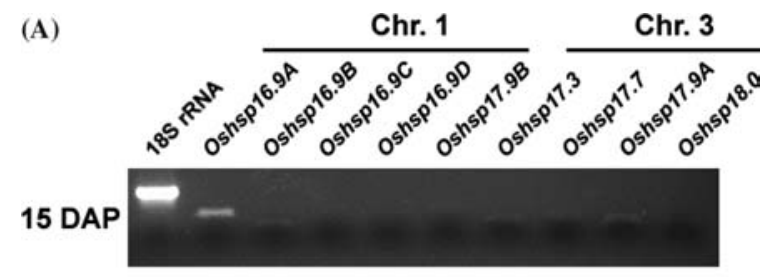

(B)

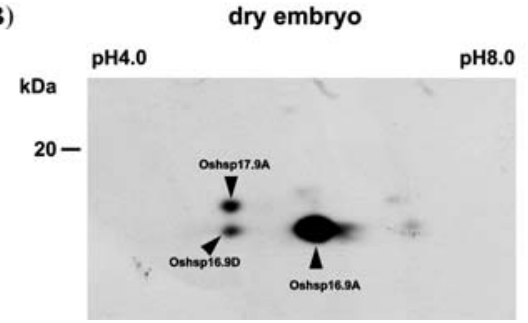

Figure 7. Expression of rice sHSP-CI gene family members during seed maturation. (A) Seed samples were harvested at 15 DAP for RT-PCR analysis. The grains began to turn brown. (B) Identification of the sHSP-CIs by 2-DE and western blotting analysis of total proteins from dry embryos separated from mature seeds. One hundred micrograms of total proteins were loaded for analysis. The chemiluminescent reagents were used for immunological detection. Exposure time to chemiluminescent film was $30 \mathrm{~s}$.

Oshsp17.3, Oshsp17.7, and Oshsp17.9A were also detected during this period but to a lesser extent. Western blotting analyses of the dry embryo proteins indicated the prominent accumulation of Oshsp16.9A protein (Figure 7B).

\section{Discussion}

\section{Rice sHSP-CI gene family}

This study presents genomic organization information of a nine members of the sHSP-CI gene family in rice. Compared to Arabidopsis, which has six members of sHSP-CI family (Scharf et al., 2001); rice sHSP-CI family has nine members. Whether all members of the rice family exist in the HSC is not clear. In our previous study, mixture of HSCs from rice and soybean after dissociation with urea could reform HSCs with an intermediate molecular mass (Jinn et al., 1995). We proposed that hetero-oligomers could be formed in plants. Our current study indicates that at least seven members of sHSP-CI family are present in the $\mathrm{HSCs}$ in rice (Figure 2B).

In Arabidopsis, sHSP-CI and CI-related genes are dispersed among all five chromosomes (Scharf et al., 2001). In contrast, rice sHSP-CI genes are divided into two groups clustered on two loci on chromosome 1 and 3. Phylogenetic and expression analyses indicate that sHSP-CI genes clustered on a chromosome more resemble to each other than to those on other chromosome in rice. This suggests that genes on individual chromosomes may have been duplicated independently. The two groups of rice sHSP-CIs belong to two of the three clades of sHSPs found in monocots. The amino acid alignment implies the wheat sHSP-CIs are very similar to Oshsp16.9A. Oshsp16.9B, and Oshsp16.9C (data not shown). The reason for the absence of rice members in the third clades may be resulted from an inserted motif between the residues 33 and 37 in the wheat clade, which is different from the rice clades.

\section{Heat shock response}

In Arabidopsis and spinach, the HSP70 genes respond rapidly to heat shock (Sung et al., 2001). In our current study, some of the rice sHSP-CI genes have relatively faster response kinetics than the other gene family members (Figures 3 and 4). It has been reported that the regulation of HSP gene expression is at the transcriptional level and in an autoregulatory manner (Schöffl et al., 1998). Thus, after reaching a peak induction during prolonged exposure to heat shock, the levels of HSP gene transcripts were reduced (Figure 5). The expression of heat shock genes is mainly attributed to activation of Hsf under heat stress. Clusters of HSE modules, which mediate efficient binding of Hsf, require at least two modules (5'-nGAAnnTTCn-3') (Schöffl et al., 1998; Nover et al., 2001). The numbers of HSEs in the promoters were correlated with the expression levels of rice sHSP-CI genes. At least three clusters of HSE modules were found in the promoter regions of sHSP-CI genes, which were strongly induced by HS treatment (Figure 1F). In contrast, low expression levels of Oshsp16.9D and Oshsp $17.9 \mathrm{~B}$ could be contributed to lacking efficient HSEs in these two genes (Figure 1F). Oshsp17.3 and Oshsp 18.0 share a $356 \mathrm{bp}$ bi-directional promoter with one perfect and seven imperfect HSEs predicted between the two TATA boxes (Figure 1D and F). We noticed that these elements were functional in both directions and resulted in transient expression of GUS activity in response to $\mathrm{HS}$ treatment (Figure 6). 
Plants contain more Hsf genes than animals, which have only one to four genes encoding Hsf. The Arabidopsis genome contains 21 copies of Hsf, whereas more than 23 copies are found in the rice genome (Nover et al., 2001; Kotak et al., 2004). A distinct feature of the plant Hsf family is that the expression of several but not all of its members is heat-induced, and this feature suggests a multi-step mechanism of Hsf involvement in the HS response. Accumulated evidences indicate that the formation of heterocomplexes among Hsfs synergistically activates the HSP promoters (Rojas et al., 2002; He et al., 2003). Genetic evidences indicated that AtHsfAla and AtHsfAlb are fast response regulators that may be important for coordination of stress gene expressions and generation of stress tolerance under rapidly changing environmental conditions in natural habitats (Lohmann et al., 2004). Thus, it is interesting to study whether rice Hsfs are involved in the differential expression of the sHSP-CI gene family members under heat shock response.

\section{HS-like response induced by chemical inducers}

Despite of the extensive studies of cross-tolerance conferred by HSPs in yeast and animals, little information is available for sHSPs in plants (Kuo et al., 2000). In the current study, most of the sHSP-CI genes were expressed in response to As treatment (Figure 5A). In contrast, Aze, Cd, and ethanol treatments induced only the genes clustered on chromosome 3 (Figure 5A). This suggests that the induction mechanisms may be different among As and $\mathrm{Cd}$, Aze, or ethanol treatments. In addition, the expression kinetics following Aze treatment is different from that of $\mathrm{Cd}$ treatment (data not shown). This indicates that the inducing, sustaining, and repressing mechanisms are also different from that of $\mathrm{Cd}$ and As treatment. The regulatory mechanisms controlling transcriptional induction, translational preference, and repression of the HS-like response in soybean seedlings are affected differently between $\mathrm{As}$ and $\mathrm{Cd}$ treatments (Edelman et al., 1988). Although downstream events in HS signal transduction pathways have been investigated in plants, little is known about how the HS signal is perceived and transduced for the activation of HSP genes (Sung et al., 2003). ABI3,
MAP kinases, $\mathrm{Ca}^{2+}$ and calmodulin have been proposed to be important components upstream in the expression of some sHSP genes in plants (Kovtun et al., 2000; Wehmeyer and Vierling, 2000; Agrawal et al., 2002; Liu et al., 2003; Li et al., 2004). So, it is possible that there are several signal transduction pathways responsible for sHSP induction in plant cells, and these pathways may be interlinked with other stress responses. Alternatively, plant Hsf and HSE could be involved in gene regulation under different stresses and perhaps play an interlinking role between heat and other stresses. The specific sequence of HSE in $H a$ hsp 17.6 Gl and preferential transcriptional activation by HaHsfA9 were shown to be crucial for Hsf promoter selectivity in developmental regulation and stress response (Almoguera et al., 2002; Rojas et al., 2002). HSEs were also shown to contribute partially to the induction of the genes by oxidative stress (Storozhenko et al., 1998). Nevertheless, clusters of canonical HSE modules were found in the promoters of Oshsp16.9A and Oshsp17.3 or Oshp18.0; however, results of transient expression assays indicated that the canonical HSEs might not be sufficient for the selective induction by Aze or other stress agents (Figure 6). It is conceivable that plant Hsfs have diversified during evolution in parallel with the sequences of the HSEs. Promoter discrimination by different Hsfs has been proposed to explain the differential transcription of sHSP genes during plant development (Rojas et al., 2002). Thus, discrimination may also be crucial for Aze treatment, and might require additional transcription factors.

\section{Role of $\mathrm{H}_{2} \mathrm{O}_{2}$ in the selective induction of rice sHSP-CI genes}

Abiotic stresses such as drought, salinity, extreme temperatures, chemical toxicity, and oxidative stress are often interconnected and may result in similar cellular damages. As a consequence, these diverse environmental stresses often activate similar cell signaling pathways (Sung et al., 2003; Wang et al., 2003). Recent evidence has demonstrated that $\mathrm{H}_{2} \mathrm{O}_{2}$ serves as a cellular signaling molecule in plants and acts through the MAPK cascades to turn on stress-related genes including sHSP genes (Kovtun et al., 2000; Rentel et al., 2004; Shou et al., 2004). It was not known whether 
all members of the sHSP gene family were induced by ROS-generated stress in plants. The current study shows that heat stress evokes the accumulation of ROS in plants; however, $\mathrm{H}_{2} \mathrm{O}_{2}$ treatment selectively induced the expression of rice sHSP-CI genes in plants.

\section{Acknowledgements}

We thank Drs. Joe. L. Key, and Anthony H.-C. Huang for critical reading of the manuscript. This work was supported by the grants nos. NSC902311-B-002-034 and NSC91-2311-B-002-056 to C.Y. Lin from the National Science Council of Taiwan.

\section{References}

Agrawal, G., Rakwal, R. and Iwahashi, H. 2002. Isolation of novel rice (Oryza sativa L.) multiple stress responsive MAP kinase gene, OsMSRMK2, whose mRNA accumulates rapidly in response to environmental cues. Biochem .Biophys. Res. Commun. 294: 1009-1016.

Almoguera, C., Prieto-Dapena, P. and Jordano, J. 1998. Dual regulation of a heat shock promoter during embryogenesis: stage-dependent role of heat shock elements. Plant J. 13: $437-446$.

Almoguera, C., Rojas, A., Díaz-Martín, J., Prieto-Dapena, P., Carranco, R. and Jordano, J. 2002. A seed-specific heatshock transcription factor involved in developmental regulation during embryogenesis in sunflower. J. Biol. Chem. 277: 43866-43872.

Banzet, N., Richaud, C., Deveaux, Y., Kazmaier, M., Gagnon, J. and Triantaphylidès, C. 1998. Accumulation of small heat shock proteins, including mitochondrial HSP22, induced by oxidative stress and adaptive response in tomato cells. Plant J. 13: 519-527.

Chang, P.F.L., Huang, C.I., Chang, F.C., Tseng, T.S., Lin, W.C. and Lin, C.Y. 2001. Isolation and characterization of the third gene encoding a $16.9 \mathrm{kDa}$ class I low-molecularmass heat shock protein, Oshsp16.9C, in rice. Bot. Bul. Acad. Sin. 42: 85-92.

Cheong, Y.H., Chang, H.S., Gupta, R., Wang, X., Zhu, T. and Luan, S. 2002. Transcriptional profiling reveals novel interactions between wounding, pathogen, abiotic stress, and hormonal responses in Arabidopsis. Plant Physiol. 129: 661677.

Desikan, R., Mackerness, S.A.H., Hancock, J.T. and Neill, S.J. 2001. Regulation of the Arabidopsis transcriptome by oxidative stress. Plant Physiol. 127: 159-172.

Edelman, L., Czarnecka, E. and Key, J.L. 1988. Induction and accumulation of heat shock-specific poly $\left(\mathrm{A}^{+}\right)$RNAs and proteins in soybean seedlings during arsenite and cadmium treatments. Plant Physiol. 86: 1048-1056.

Guan, J.C., Li, X.H., Zhang, Q.F., Kochert, G. and Lin, C.Y. 2003. Characterization of a unique genomic clone located $5^{\prime}$ upstream of the $O s h s p 16.9 B$ gene on chromosome 1 in rice (Oryza sativa L. cv Tainung No.67). Theor. Appl. Genet. 106: 503-511.
Haslbeck, M., Braun, N., Stromer, T., Richter, B., Model, N., Weinkaul, S. and Buchner, J. 2004. Hsp42 is the general small heat shock protein in the cytosol of Saccharomyces cerevisiae. EMBO J. 23: 638-649.

He, H., Sonicn, F., Grammatikakis, N., Li, Y., Siganou, A., Gong, J., Brown, S.A., Kingston, R.E. and Calderwood, S.K. 2003. Elevated expression of heat shock factor (HSF) 2A stimulates HSF1-induced transcription during stress. J. Biol. Chem. 278: 35465-35475.

Hong, S.K. and Vierling, E. 2000. Mutants of Arabidopsis thaliana defective in the acquisition of tolerance to high temperature stress. Proc. Natl. Acad. Sci. USA 97: 43924397.

Hsieh, M.S., Chen, J.T., Jinn, T.L., Chen, Y.M. and Lin, C.Y. 1992. A class of soybean low molecular weight heat shock proteins. Plant Physiol. 99: 1279-1284.

Jinn, T.L., Chen, Y.M. and Lin, C.Y. 1995. Characterization and physiological function of class I low-molecular-mass, heat-shock protein complex in soybean. Plant Physiol. 108: 693-701.

Jofré, A., Molinas, M. and Pla, M. 2003. A 10-kDa class-CI sHsp protects $E$. coli from oxidative and high-temperature stress. Planta 217: 813-819.

Key, J.L., Lin, C.Y. and Chen, Y.M. 1981. Heat shock proteins of higher plants. Proc. Natl. Acad. Sci. USA 78: 3526-3530.

Kotak, S., Port, M., Ganguli, A., Bicker, F. and von KoskullDoring, P. 2004. Characterization of C-terminal domains of Arabidopsis heat stress transcription factors (Hsfs) and identification of a new signature combination of plant class A Hsfs with AHA and NES motifs essential for activator function and intracellular localization. Plant J. 39: 98-112.

Kovtun, Y., Chiu, W.L., Tena, G. and Sheen, J. 2000. Functional analysis of oxidative stress-activated mitogenactivated protein kinase cascade in plants. Proc. Natl. Acad. Sci. USA 97: 2940-2945.

Kuo, H.F., Tsai, Y.F., Young, L.S. and Lin, C.Y. 2000. Ethanol treatment triggers a heat shock-like response but no thermotolerance in soybean (Glycine $\max$ cv. Kaohsiung No.8) seedlings. Plant Cell Environ. 23: 1099-1108.

Lee, Y.L., Chang, P.F.L., Yeh, K.W., Jinn, T.L., Kung, C.C.S., Lin, W.C., Chen, Y.M. and Lin, C.Y. 1995. Cloning and characterization of a cDNA encoding an 18.0-kDa class-I low-molecular-weight heat-shock protein from rice. Gene 165: 223-227.

Lee, Y.R.J., Nagao, R.T., Lin, C.Y. and Key, J.L. 1996. Induction and regulation of heat-shock gene expression by an amino acid analog in soybean seedlings. Plant Physiol. 110: 241-248.

Lee, B.H., Won, S.H., Lee, H.S., Miyao, M., Chung, W.I., Kim, I.J. and Jo, J. 2000. Expression of the chloroplastlocalized small heat shock protein by oxidative stress in rice. Gene 245: 283-290.

Li, B., Liu, H.T., Sun, D.Y. and Zhou, R.G. 2004. $\mathrm{Ca}^{2+}$ and calmodulin modulate DNA-binding activity of maize heat shock transcription factor in vitro. Plant Cell Physiol. 45: 627-634.

Lin, C.Y., Roberts, J.K. and Key, J.L. 1984. Acquisition of thermotolerance in soybean seedlings 1 . Synthesis and accumulation of heat shock proteins and their cellular localization. Plant Physiol. 74: 152-160.

Liu, H.T., Li, B., Shang, Z.L., Li, X.Z., Mu, R.L., Sun, D.Y. and Zhou, R.G. 2003. Calmodulin is involved in heat shock signal transduction in wheat. Plant Physiol. 132: 1186-1195. 
Lohmann, C., Eggers-Schumacher, G., Wunderlich, M. and Schöffl, F. 2004. Two different heat shock transcription factors regulate immediate early expression of stress genes in Arabidopsis. Mol. Gen. Genom. 271: 11-21.

Lubaretz, O. and zur Nieden, U. 2002. Accumulation of plant small heat-stress proteins in storage organs. Planta 215: 220-228.

Maestri, E., Klueva, N., Perrotta, C., Gulli, M., Nguyen, H.T. and Marmiroli, N. 2002. Molecular genetics of heat tolerance and heat shock proteins in cereals. Plant Mol. Biol. 48: 667-681.

Malik, M.K., Slovin, J.P., Hwang, C.H. and Zimmerman, J.L. 1999. Modified expression of a carrot small heat shock protein gene, Hsp 17.7, results in increased or decreased thermotolerance. Plant J. 20: 89-99.

Nakamoto, H., Susuki, N. and Roy, S.K. 2000. Constitutive expression of a small heat-shock protein confers cellular thermotolerance and thermal protection to the photosynthetic apparatus in cyanobacteria. FEBS Lett. 483: 169-174.

Nover, L., Bharti, K., Doring, P., Mishra, S.K., Ganguli, A. and Scharf, K.D. 2001. Arabidopsis and the heat stress transcription factor world: How many heat stress transcription factors do we need? Cell Stress Chaperon. 6: 177-189.

Panchuk, I.I., Volkov, R.A. and Schöffl, F. 2002. Heat stressand heat shock transcription factor-dependent expression and activity of ascorbate peroxidase in Arabidopsis. Plant Physiol. 129: 838-853.

Plesofsky-Vig, N. and Brambl, R. 1995. Disruption of the gene for hsp30, an $\alpha$-crystallin-related heat shock protein of Neurospora crassa, causes defects in thermotolerance. Proc. Natl. Acad. Sci. USA 92: 5032-5036.

Rentel, M.C., Lecourieux, D., Ouaked, F., Usher, S., Petersen, L., Okamoto, H., Knight, H., Peck, S.C., Grierson, C., Hirt, H. and Knight, M.R. 2004. OXI1 kinase is necessary for oxidative burst-mediated signaling in Arabidopsis. Nature 427: 858-861.

Rojas, A., Almoguera, C., Carranco, R., Scharf, K.D. and Jordano, J. 2002. Selective activation of the developmentally regulated Hahsp17.6 G1 promoter by heat stress transcription factors. Plant Physiol. 129: 1207-1215.

Sabehat, A., Lurie, S. and Weiss, D. 1998. Expression of small heat-shock proteins at low temperatures. Plant Physiol. 117: $651-658$.

Sanmiya, K., Suzuki, K., Egawa, Y. and Shono, M. 2004 Mitochondrial small heat-shock protein enhances thermotolerance in tobacco plants. FEBS Lett. 557: 265-268.

Scharf, K.D., Siddique, M. and Vierling, E. 2001. The expanding family of Arabidopsis thaliana small heat stress proteins and a new family of proteins containing crystalline domains (Acd proteins). Cell Stress Chaperon. 6: 225-237.

Schöffl, F., Prändl, R. and Reindl, A. 1998. Regulation of the heat-shock response. Plant Physiol. 117: 1135-1141.

Shen, Q.X., Zhang, P.N. and Ho, T.H.D. 1996. Modular nature of abscisic acid (ABA) response complexes: composite promoter units that are necessary and sufficient for ABA induction of gene expression in barley. Plant Cell 8: 1107-1119.

Shou, H.X., Bordallo, P., Fan, J.B., Yeakley, J.M., Bibikova, M., Sheen, J. and Wang, K. 2004. Expression of an active tobacco mitogen-activated protein kinase kinase kinase enhances freezing tolerance in transgenic maize. Proc. Natl. Acad. Sci. USA 101: 3298-3303.

Storozhenko, S., Pauw, P.D., Van Montagu, M., Inze, D. and Kushnir, S. 1998. The heat-shock element is a functional component of the Arabidopsis $A P X 1$ gene promoter. Plant Physiol. 118:1005-1014.

Sung, D.Y., Vierling, E. and Guy, C.L. 2001. Comprehensive expression profile analysis of the Arabidopsis Hsp70 gene family. Plant Physiol. 126: 798-800.

Sung, D.Y., Kaplan, F., Lee, K.J. and Guy, C.L. 2003. Acquired tolerance to temperature extremes. Trends Plant Sci. 8: 179-187.

Tseng, T.S., Tzeng, S.S., Yeh, K.W., Yeh, C.H., Chang, F.C., Chen, Y.M. and Lin, C.Y. 1993. The heat-shock response in rice seedlings: isolation and expression of cDNAs that encode class I low-molecular-weight heat-shock proteins. Plant Cell Physiol. 34: 165-168.

Tzeng, S.S., Chen, Y.M. and Lin, C.Y. 1993. Isolation and characterization of genes encoding $16.9 \mathrm{kD}$ heat shock proteins in Oryza sativa. Bot. Bull. Acad. Sin. 34: 133-142.

van Montfort, R.L.M., Basha, E., Friedrich, K.L., Slingsby, C. and Vierling, E. 2001. Crystal structure and assembly of a eukaryotic small heat shock protein. Nat. Struct. Biol. 8: 1025-1030.

Wang, W.X., Vinocur, B. and Altman, A. 2003. Plant response to drought, salinity and extreme temperatures: towards genetic engineering for stress tolerance. Planta 218: 1-14.

Wehmeyer, N. and Vierling, E. 2000. The expression of small heat shock proteins in seeds responds to discrete developmental signals and suggests general protective role in desiccation tolerance. Plant Physiol. 122: 1099-1108.

Yeh, C.H., Yeh, K.W., Wu, S.H., Chang, P.F.L., Chen, Y.M. and Lin, C.Y. 1995. A recombinant rice 16.9-kDa heat shock protein can provide thermoprotection in vitro. Plant Cell Physiol. 36: 1341-1348. 